\title{
Cystic Neck Swellings in Pediatric: Pattern of Presentation and Outcome After Surgery, Case Series Study
}

\author{
Original Kamal A. A. M. Hassanein', Omar A. El Tabary', Amir A. M. M. AL-Sakaty \\ Article Mohammed Yousef Batikhe ${ }^{4}$, Islam A. Amer \\ ${ }^{1,5}$ Maxillofacial, Head and Neck Surgery Unit 8i, ${ }^{2,3}$ General Surgery Department, ${ }^{4}$ Pediatric \\ Surgery Department, Faculty of Medicine, Sohag University, Egypt
}

\begin{abstract}
Background: The aim of this research was to assess the pattern of presentation and outcome of Cystic neck swelling in pediatric patients following surgery.

Patients and Methods: This study included 126 patients (69 males and 57 females) their age ranged from 9 days to 16 years with cystic neck swellings and had been treated by Excision in surgical procedure in the Maxillofacial/Head and Neck Surgical Unit, Pediatric Surgery Unit at Sohag University Hospitals, in the period from March 2014 to March 2019. Analysis of the clinical presentation, the type of neck swelling was done. All patients were eligible for this study.

Results: Total of 126 cases were included in this study, Majority of cases present as midline neck swelling $90(71.4 \%)$ and $31(24.6 \%)$ as lateral neck swelling and $5(4 \%)$ as submandibular swelling, and as regard diagnosis thyroglossal cyst were $82(65.1 \%)$ and $19(15.1 \%)$ were cystic hygroma and $16(12.7 \%)$ were branchial cyst (10 left and 5 right and 1 bilateral) and $8(6.3 \%)$ were dermoid cyst, and one case $(0.8 \%)$ were cystic teratoma

Conclusion: Surgical resection is the best treatment option not only for esthetic purposes but also to get rid of the recurrent infection and risk of fistula formation and possible pressure on neck structures.
\end{abstract}

Key Words: Cystic swellings, neck, pediatric.

Received: 27 October 2020, Accepted: 31 December 2020

Corresponding Author: Islam A. Amer, MD, Department of General Surgery, Faculty of Medicine, Sohag University, Egypt, Tel.: 01017766441, E-mail: dr.islamamer1981@gmail.com

ISSN: 2090-0740, 2021 Vol.22

\section{INTRODUCTION}

In children, a neck mass most commonly represents a congenital neck lesion, inflammatory, or reactive pathology. Malignancy is less common and represents approximately $10 \%$ of pediatric neck masses. The operative resection is the mainstay of therapy for both diagnostic and therapeutic purposes $^{[1]}$.

The prevalence of these lesions varies from popular (thyroglossal duct cysts, branchial cleft cysts, and cyst hygromas) to very rare (thymic and cervical bronchogenic cysts) $)^{[2]}$.

Each type of mass has a characteristic appearance and location in the neck. Such masses are categorized as lateral neck masses (including branchial cyst and laryngocele), midline neck masses (including thyroglossal duct cyst, thymic cyst, dermoid cyst, and teratoma of the neck), and whole neck masses (including hemangioma and lymphangioma $)^{[3]}$.

Most are asymptomatic, Commonly, they are observed by patient parents, or unexpectedly during routine physical examinations. in all cases neck us is mandatory but also
CT and MRI can be used in selected cases needed for $\operatorname{diagnosis}^{[4]}$.

Management of these lesions begins with a detailed understanding of the Head and Neck embryology, Imaging is often a useful adjunct to a thorough head and neck examination; however, there are special considerations in the pediatric age group ${ }^{[1]}$.

In children, Thyroglossal duct cyst comprises approximately $70 \%$ of all Congenital neck lesions, making it the commonest congenital abnormality of the neck, the cyst presents as a midline neck mass ${ }^{[5]}$.

Branchial cleft anomalies are the second most common head and neck congenital lesions in children, composed approximately $30 \%$ of congenital neck disease ${ }^{[6]}$.

Dermoid cysts are commonly found on the face and head, but also frequently present in the neck midline in the submental region, and although attached to overlying skin are painless until infected ${ }^{[7,8]}$. 
Cystic hygroma is the commonest cystic neck mass involving the posterior cervical space $(75 \%-80 \%)$. The other common site in children is the oral cavity ${ }^{[9]}$ the cystic hygroma most frequently presents in the neck as painless, soft, or moderately firm masses of highly variable size ${ }^{[10]}$.

Neck teratoma is an unusual site, most of them present as midline involvement and they have a relationship with the thyroid gland. Many congenital cervical teratomas might be mistaken for cystic hygroma ${ }^{[11]}$.

Infected cysts are first managed by relieving the infection. The cysts are usually infected via the mouth, Antibiotic coverage should be initiated, and needle aspiration may be indicated to allow for decompression and identification of the causal organism.Formal incision and drainage should be avoided, if possible, to prevent seeding of ductal cells outside the cyst, which may increase the risk of recurrence ${ }^{[12]}$.

\section{PATIENTS AND METHODS:}

This prospective study include pediatric patients with cystic neck swellings and had been treated by surgical excision in the Maxillofacial/Head and Neck Surgical Unit, Pediatric Surgery Unit at Sohag University Hospitals, in the period from March 2014 to March 2019.

All cases had been Denovo diagnosed at Sohag University Hospitals.

Preoperative data concerning: age, gender, presentation, associated anomalies, family history, associated symptoms. All the surgical procedures were done with endotracheal intubation under general anesthesia.

The following data were collected; age at the time of treatment, gender, presenting symptoms, the extent of the lesion, radiologic investigations performed. The diagnosis was made clinically and by ultrasound scan in all cases, CT and MRI in selected cases.

The Ultimate diagnosis verified by histopathological evaluation after the excision of the lesion. Surgery aimed to achieve complete resection of the disease whenever possible.

All cases were evaluated for: recurrence, complications.

\section{RESULTS:}

A total of 126 patients were admitted to Maxillofacial/ Head and Neck Surgical Unit, Pediatric Surgery Unit at Sohag University Hospital complaining of cystic neck swelling from March 2014 to March 2019, their age ranged from 9 days to 16 years, mean for age were $6.81 \pm 4.88$ at time of presentation, of them $69(54.7 \%)$ were males and $57(45.23 \%)$ were females.

The majority of the cases were thyroglossal cyst 82 $(65.1 \%)$ and $19(15.1 \%)$ were cystic hygroma and 16 $(12.7 \%)$ were branchial cyst (10 left and 5 right and 1 bilateral) and $8(6.3 \%)$ were dermoid cyst, and one case $(0.8 \%)$ were cystic teratoma.

Majority of cases present as midline neck swelling 90 $(71.4 \%)$ and $31(24.6 \%)$ as lateral neck swelling and 5 (4\%) as submandibular swelling.

Majority of cases $116(92 \%)$ presented as painless neck mass and $9(7.2 \%)$ as repeated neck infection and $1(0.8 \%)$ as dyspnea.

Diagnostic imaging was done as neck ultrasound done in all cases, CT has done in $32(25.6 \%)$ and MRI has done in $2(1.6 \%)$.

Sistrunk operation was done for all cases of thyroglossal cyst $82(65.6 \%)$ and Complete excision of the lesion was obtained in the rest of the cases 43 (34.3\%).

Overall complications rate was encountered in 9 patients $(7.15 \%)$ as one case of thyroglossal cyst complicated by fistula $(0.8 \%)$ and one case of cystic hygroma complicated as infected wound $(0.8 \%)$ and one complicated by seroma formation $(0.8 \%)$ and recurrence were in four cases of the thyroglossal cyst $(3.17 \%)$ and two cases of cystic hygroma $(1.6 \%)$.

Family history was encountered only in five cases (0.8\%). (Figs. 1-11).

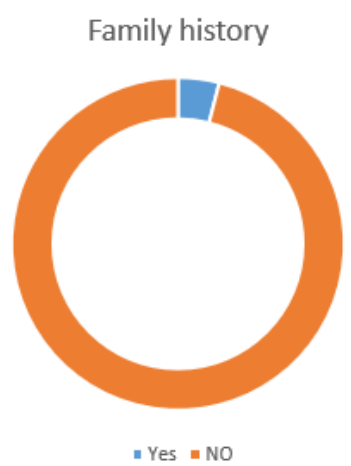




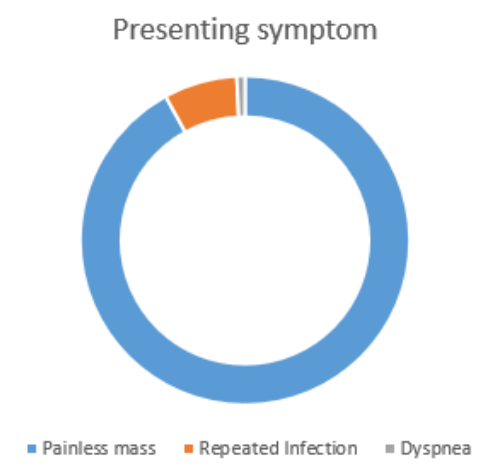

Presentation site

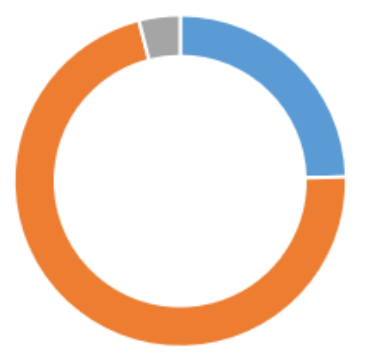

- latral neck swelling = midline neck swelling

- submandibular neck swelling

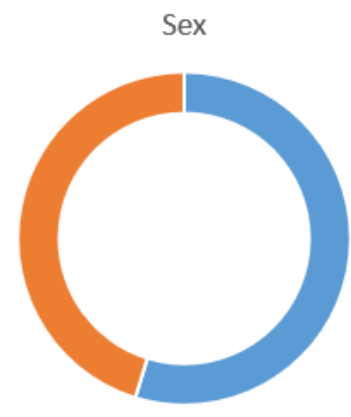

- Male I Female

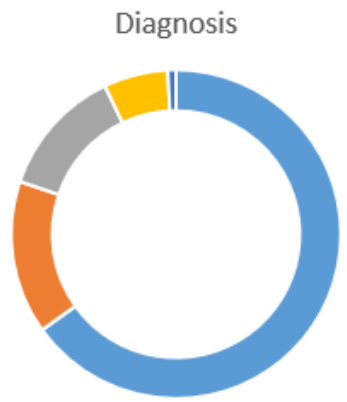

- Thyroglossal cyst | Cystic hygroma | Branchial cyst || Dermoid cyst = Cystic teratoma

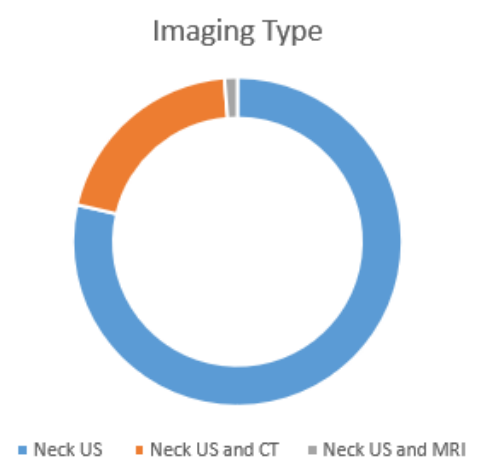

Complications

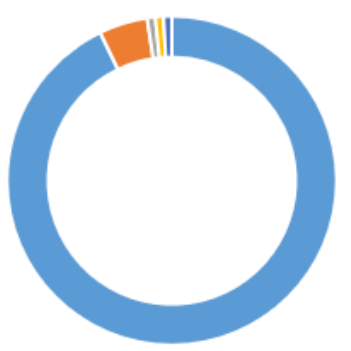

- NO - recurrence | fistula "| seroma " infected wound

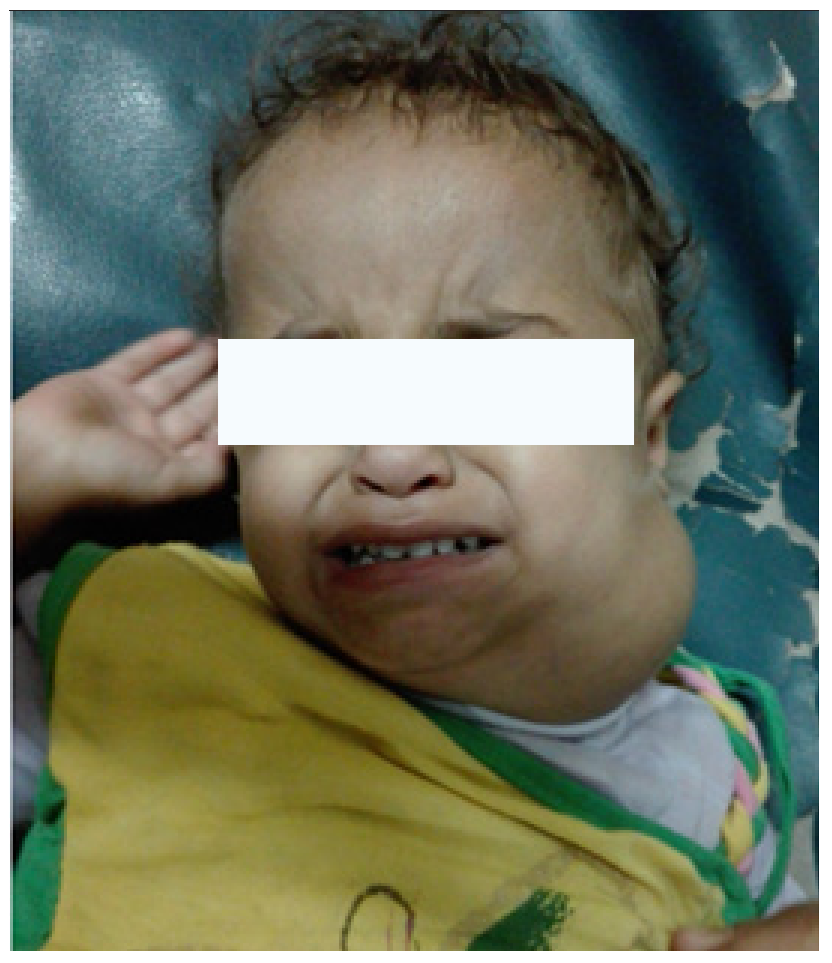

Image 1 : showing large second branchial cyst 


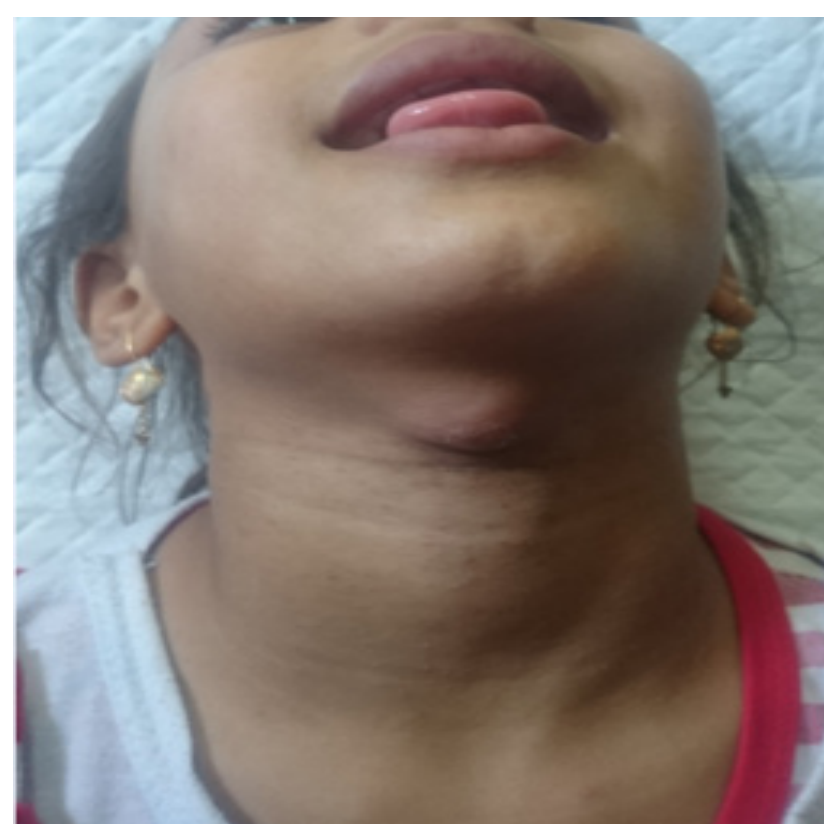

Image 2: showing thyroglossal cyst

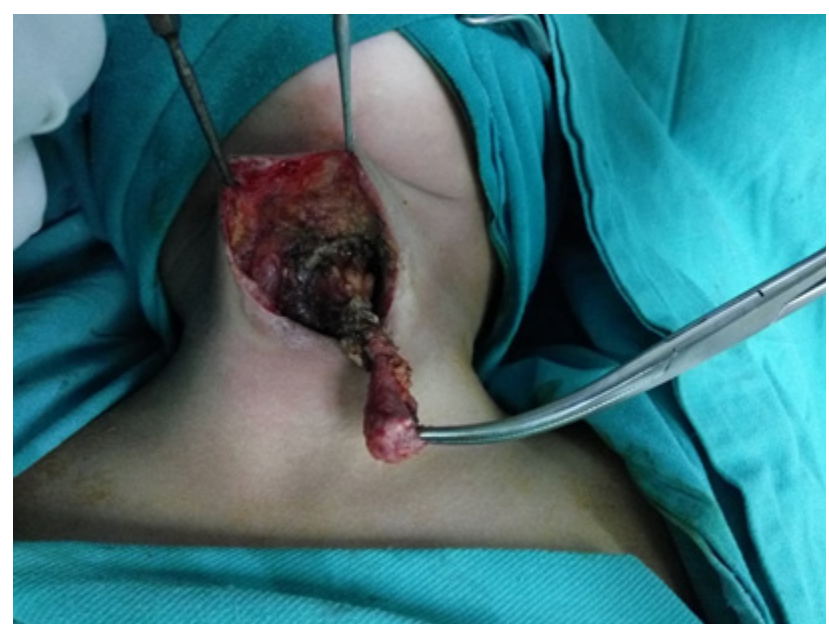

Image 3: showing thyroglossal cyst dissection till hyoid bone

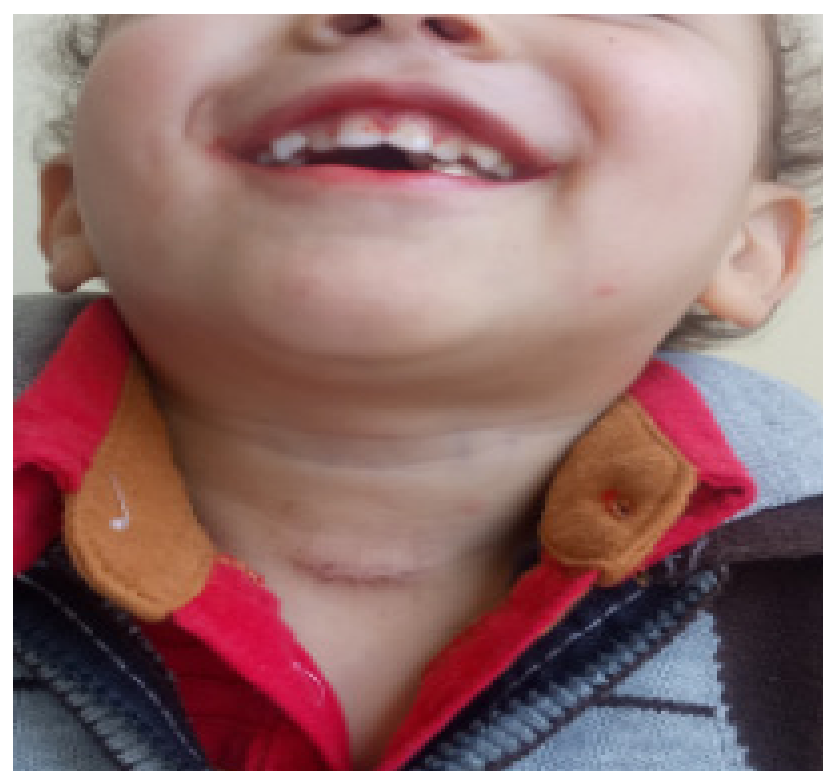

Image 4: showing dermoid cyst

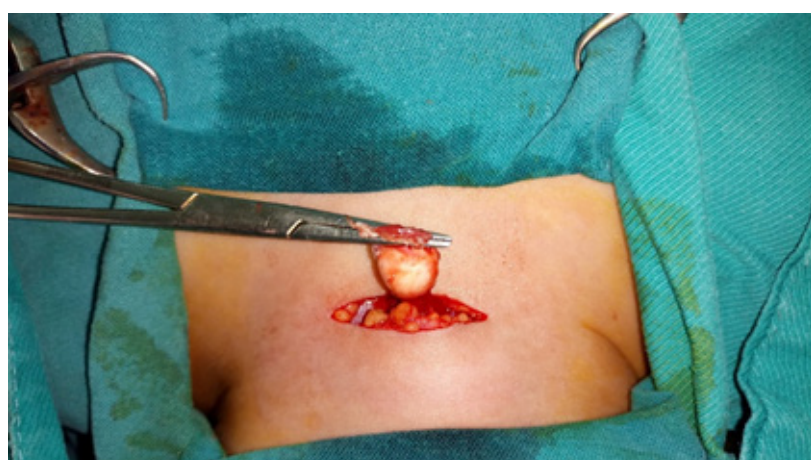

Image 5: showing dermoid cyst excision

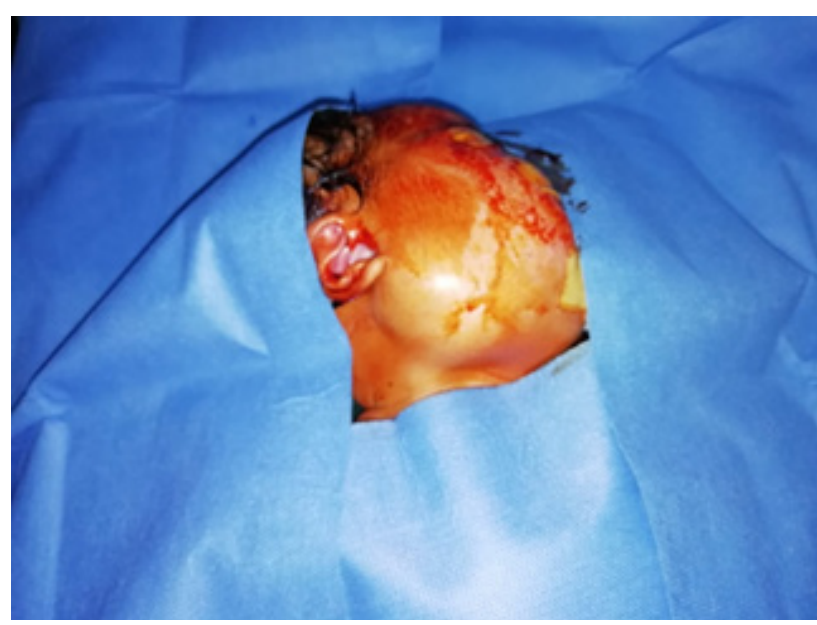

Image 6: showing cystic teratoma

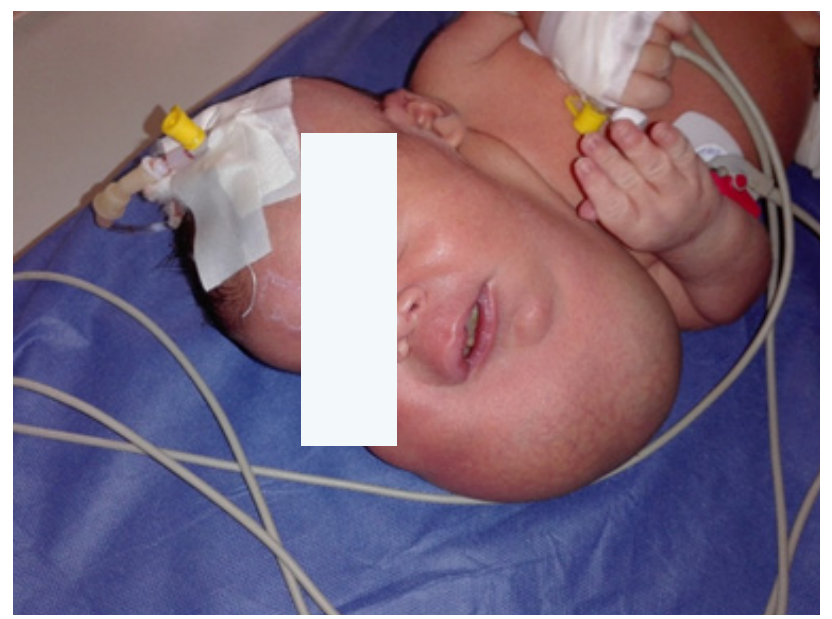

Image 7: showing huge cystic hygroma

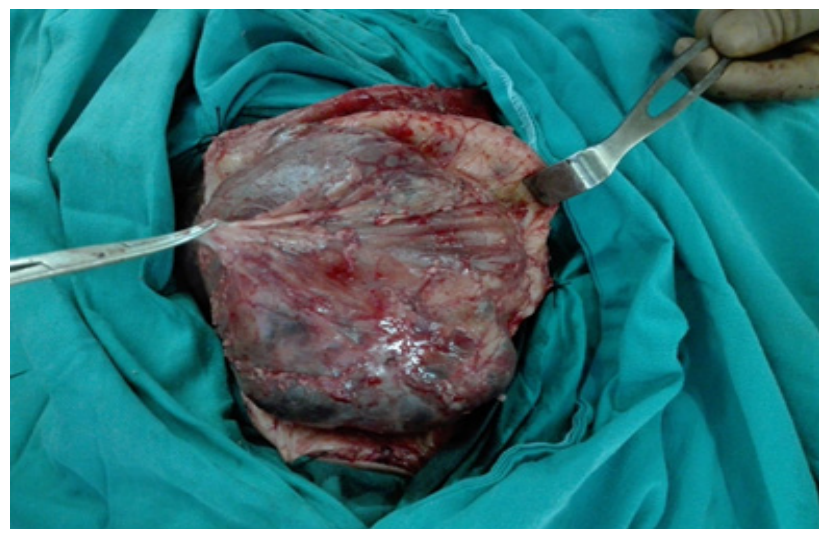

Image 8: showing intraoperative dissection of cystic hygroma 


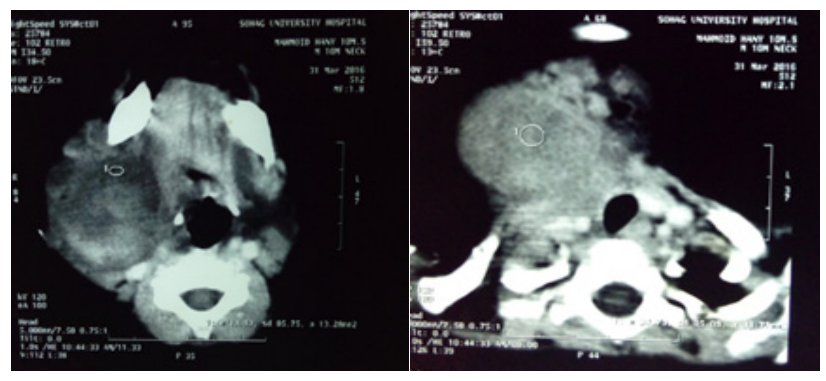

Image 9: cystic hygroma CT

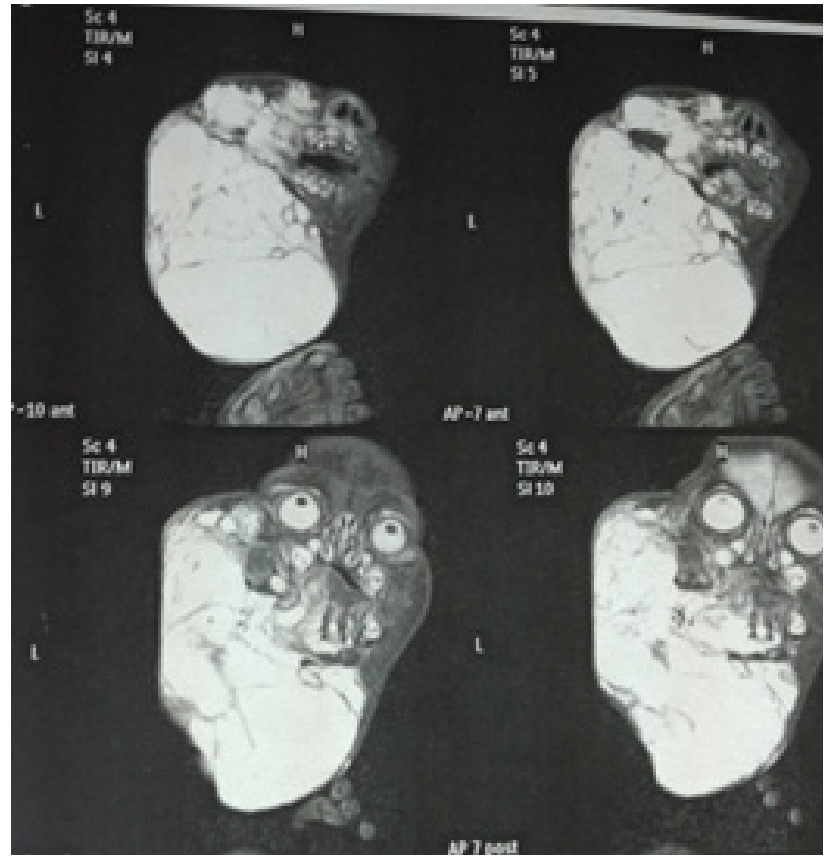

Image 10: huge cystic hygroma MRI

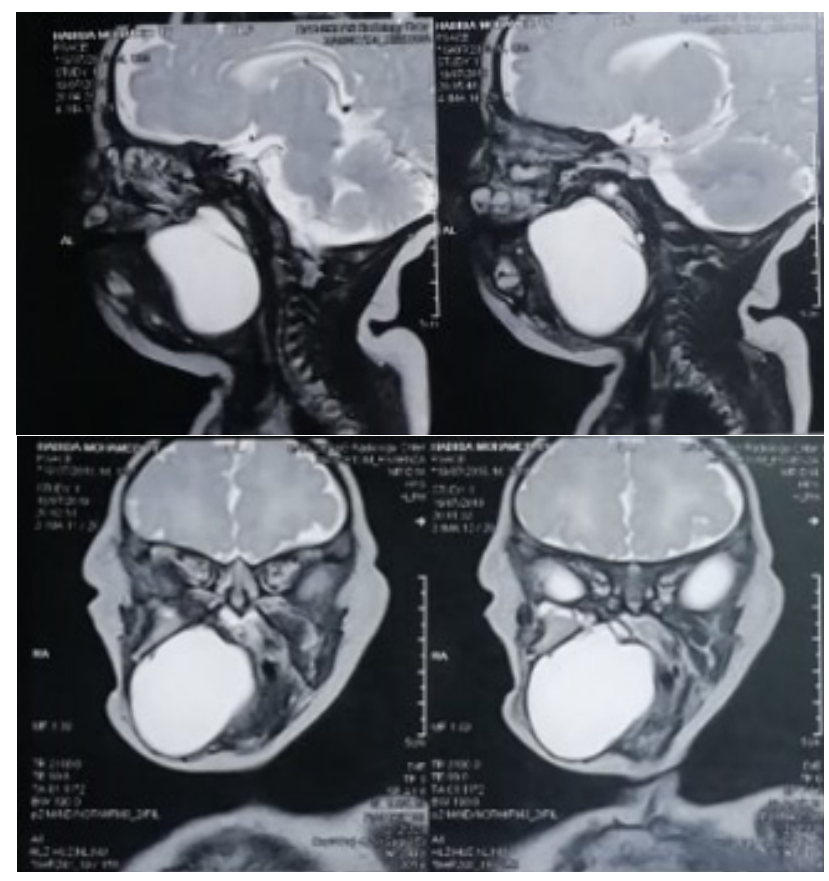

Image 11: cystic teratoma MRI

\section{DISCUSSION}

Results of our study prove that congenital cystic neck swellings are more common in males $(55 \%)$ than females $(45 \%)$.

Our study revealed that thyroglossal cyst more common in males than females $(59 \%$ were males and $41 \%$ were females), and the same described by Ross et al., 2017 as the percentage was 51\% male, 49\% female. However, up to our knowledge, there has not been any explanation for that difference.

Majority of cases present as midline neck swelling which is the same as (Ayugi et al., 2010)., which are Thyroglossal duct cyst.

Spinelli et al., 2016 described that all patients presented with a neck swelling, which was painless in the majority of cases and painful when infection was present, and that is nearly the same in our study where the majority of cases $(92 \%)$ presented as painless neck mass and $(7.2 \%)$ as repeated neck infection and $(0.8 \%)$ as dyspnea.

While Ross et al., 2017 described that (51.3\%) demonstrated additional symptoms. The most common presentation in symptomatic patients was infection $(27.8 \%)$, followed by tenderness $(17.2 \%)$, and fistula $(16.4 \%)$.

In our study thyroglossal cyst was the commonest congenital neck cyst (65\%), while in Al-Khateeb et al. study was the thyroglossal cysts account for (53\%) (Al-Khateeb et al., 2007)

Our study revealed that cystic hygroma is the second most common cystic neck swelling after Thyroglossal duct cyst, and it's more common in males $(57.9 \%)$ than females $(42.1 \%)$, others reported that the second most common swelling is second branchial cyst (Erikci and Hosgor, 2014 and Al-Khateeb et al., 2007). This explained by the cases of our study, unlike other studies, collected from both the pediatric surgery unit and the maxillofacial surgery unit.

As regards second branchial arch cysts, our study revealed that it's more common in the left side of the neck and more common in females than males and bilateral lesions account for $6.25 \%$ of cases, But in Li et al The second branchial arch cysts occur more on the right side than the left side, and males and females have the same proportion, and bilateral lesions accounted for $9 \%-11 \%$ of the second branchial arch cysts (Li et al., 2018). 
There are five cases in our study that has positive family history was a bilateral branchial cyst and Shen et al., 2018 described that branchial cleft anomalies may be bilateral in $1-3 \%$ of cases where they are often familial, and this explained by the positive consanguinity between parents in our community.

The dermoid cyst was $(6.4 \%)$, but it is close to percentage according to Al-Khateeb et al., 2007 were dermoid cyst account for $(10 \%)$.

In our study, neck ultrasound was a mandatory step in diagnosis in all cases, and that is the same in many studies like (Erikci and Hosgor, 2014; Spinelli et al., 2016).

CT imaging was done in 32 cases in our study, but in Spinelli et al., 2016 no CT scan was performed to avoid X-ray exposure to children, and this can be explained by the fact that $\mathrm{CT}$ imaging is cheaper and more available in our community in comparison with MRI imaging, but also MRI imaging was done in 4 cases in our study to evaluate the relationship with the surrounding anatomical structures.

Sistrunk operation was done for all cases of Thyroglossal duct cyst where complete excision of the cyst and part of hyoid bone was done. In a study by Ross et al., 2017 the majority of patients treated for TGDC underwent the Sistrunk's procedure (75.2\%), the remainder $(24.8 \%)$ had procedures resulting in Thyroglossal duct cyst excision but did not undergo hyoid resection and recurrence between these two groups was $11.0 \%$ and $23.3 \%$, respectively.

Reported recurrence in our cases of Thyroglossal duct cyst is (3.2\%), It is obvious that it is less than that reported by Ross et al., 2017, as we have the policy of excision of the whole cyst with the median part of the hyoid bone.

Complete surgical excision of the lesion was obtained in the rest of the cases, and that is the treatment of choice according to (Spinelli et al., 2016).

The recurrence rate for the thyroglossal cyst in Erikci and Hosgor, 2014 was (5.1\%). While in our study four cases of the thyroglossal cyst $(3.2 \%)$, on further evaluation and analysis of our cases that come back with reported recurrence, we found 3 of the 4 cases has reported infection before surgery and this is with accordance with explanation mentioned by Ross et al., 2017 that fond a great relation between recurrence and any sort of previous infections..

All cases of recurrence underwent Sistrunk operation and no other complications founded in there follow up.
No complication nor recurrence was encountered in cases of second branchial arch cysts, while Spinelli et al have 4\% recurrence rate and all have previous infections (Spinelli et al., 2016).

As regard cystic hygroma complete surgical excision was the treatment choice and the overall complications were encountered in four cases; residual lymph cyst lesion was in two cases and attributed to incomplete lesion resection as these cases were of microcystic or mixed type, which has more tendency to interdigitate into tissue planes, and its complete excision is extremely difficult and hazardous, the same was described by Hassanein et al., 2017, where recurrence rate was $(8.3 \%)$ while in our series was $(10.1 \%)$ which is lower than that described by AlKhateeb et al., 2007 (12 to 17\%).

One case has a postoperative infected wound and another one complicated by seroma formation.

\section{CONCLUSION}

Surgical resection is the optimal choice of therapy not only for aesthetic purposes but also to get rid of the recurrent infection and risk of fistula formation and possible pressure on neck structures especially in large cystic hygroma.

To minimize the risk of recurrence and complications, specialized surgeons should carry out the surgical operations in this field and follow the principles of resection of these lesions with great care to protect neuro-vascular structures and upper orodigestive tract.

We should not do surgery unless infection subsides and tissue becomes normal or near normal.

\section{ACKNOWLEDGMENTS}

The authors wish to thanks residents in the General Surgery Department at Sohag University Hospital for their help.

\section{CONFLICT OF INTEREST}

There are no conflicts of interest.

\section{REFERENCES}

1. LEE, and FERNANDES, 2008. Neck masses: evaluation and diagnostic approach. Oral and Maxillofacial Surgery Clinics of North America, 20, 321-337. 
2. KOELLER ALAMO ADAIR and SMIRNIOTOPOULOS, 1999a. From the Archives of the AFIP: Congenital cystic masses of the neck: Radiologic-pathologic correlation. Radiographics, 19, 121-146.

3. AL-KHATEEB and AL ZOUBI, 2007. Congenital neck masses: a descriptive retrospective study of 252 cases. Journal of oral and maxillofacial surgery, 65, 2242-2247.

4. FOLEY, and FALLAT, 2006 Thyroglossal duct and other congenital midline cervical anomalies. Seminars in pediatric surgery, 2006. Elsevier, 70-75.

5. IRACE, and ADIL. 2017. Embryology of congenital neck masses. 28, 138-142.

6. REGEZI, SCIUBBA, and JORDAN, 2016. Oral pathology: clinical pathologic correlations, Elsevier Health Sciences.

7. LARIVIERE, and WALDHAUSEN, 2012. Congenital cervical cysts, sinuses, and fistulae in pediatric surgery. Surg Clin North Am, 92, 583-97, viii.
8. THANUJA, AHUJA, KOHLI, DUTTA, and GUPTA, 2015. Unusual Recurrent Dermoid Cyst: A Case Report. 2, 5.

9. SJOGREN, ARNOLD, SKIRKO, and GRIMMER, 2017. Anatomic distribution of cervicofacial lymphatic malformations based on lymph node groups. International journal of pediatric otorhinolaryngology, 97, 72-75.

10. GADDIKERI, VATTOTH, GADDIKERI, STUART, HARRISON, YOUNG, et al 2014. Congenital cystic neck masses: embryology and imaging appearances, with clinicopathological correlation. Curr Probl Diagn Radiol, 43, 55-67.

11. WIN, RAZY, HAMID, UBRAMANIAN, and RAMALINGGAM, 2014. Congenital mature cystic teratoma of the lateral neck presenting as cystic hygroma: a rare case report with literature review. Turk Patoloji Derg, 30, 220-4.

12. PASHA, R. \& GOLUB, J .S. 2017. Otolaryngologyhead and neck surgery: clinical reference guide, Plural publishing. 